\title{
Potential Anti-cancer and Anti-bacterial Activities of Philippine Echinoderm Extracts
}

\author{
Rodyl J. Layson ${ }^{1}$, Maria Criselda A. Rodil ${ }^{1}$, Elmer-Rico E. Mojica ${ }^{2}$, Custer C. Deocaris ${ }^{3^{*}}$
}

\author{
${ }^{1}$ College of Science, Polytechnic University of the Philippines, Sta Mesa, Manila, Philippines \\ ${ }^{2}$ Department of Chemistry and Physical Sciences, Pace University, New York, NY, 10038, USA \\ ${ }^{3}$ Research \& Development Management Office, Technological Institute of the Philippines, Cubao, Quezon City, 1102 Philippines
}

\begin{abstract}
In high-throughput search for bioactive compounds under resource-limited settings from Philippine echinoderms, the aqueous, methanol, chloroform and hexane extracts of seven Philippine echinoderms namely Holothuria nobilis (sea cucumber), Bohadscia marmorata (sea cucumber), Stichopus chloronatus (sea cucumber), Holothuria axiologa (sea cucumber), Linckia laevigata (starfish), Oreaster nodusus (starfish) and Ophiocoma ochoenleinii (brittle star) were screened for antitumor and antibacterial activity. Antitumor activity was determined using brine shrimp lethality assay while antibacterial assay was performed using turbidimetric method. Both assays utilized 96-well microtiter plates to facilitate speed and ease in screening. The chloroform extract of $H$. nobilis gave a positive result on antitumor activity while almost all sample extracts showed antibacterial activity against E. coli.
\end{abstract}

Keywords: brine shrimp lethality, crude extracts, marine natural products, microplate screening, star fishes, anti-tumor

\section{INTRODUCTION}

Phylum Echinodermata which included sea lilies, feather stars, brittle stars, sea stars, sand dollars, sea urchins, sea biscuits and sea cucumbers, is one of the most distinct phyla of the animal kingdom. Most of the approximately 6,500 echinoderms are marine species with none of them living in freshwater [1]. Organisms that belong to this phylum were already proven to contain antibacterial, antifungal, antiviral, antitumor, anticoagulant, cytotoxic, hemolytic, antithrombotic and even anti-HIV agents (for comprehensive review and monographs see [2-6]).

The Philippines being an archipelago is surrounded by seas, which serve as habitat for wide diversity of marine invertebrates including echinoderms. Collection of these organisms for biochemical or biomedical research to further enrich the knowledge concerning local marine lives is very conducive. A lot of marine organisms remained unstudied and by exploiting them as source of drugs or chemotherapeutic agents is of great value.

This study will give pharmacological knowledge about seven Philippine echinoderms namely Holothuria nobilis (sea cucumber), Bohadscia mar-

\section{${ }^{*}$ Corresponding author:}

Custer C. Deocaris

Research \& Development Management Office, Technological Institute of the Philippines, Quezon City, 1102 Philippines

E-mail: cdeocaris@gmail.com morata (sea cucumber), Stichopus chloronatus (sea cucumber), Holothuria axiologa (sea cucumber), Linckia laevigata (starfish), Oreaster nodusus (starfish) and Ophiocoma ochoenleinii (brittle star). Different solvent extracts from these organisms will be screened and possibly be used as potential sources of antitumor and antibacterial agents.

\section{MATERIALS AND METHODS \\ Materials}

Echinoderms were gathered in Dimasalang, Masbate, from the shallow up to deeper parts of the sea. Each sample was washed with water to remove dirt and sand. Samples were individually packed in polypropylene bags and curated in the National Museum (Manila, Philippines).

\section{Extraction}

Frozen samples were homogenized using a waring blender upon addition of ample amount of water. The homogenate was centrifuged and the collected supernatant was lyophilized. The collected extracts were stored at $-20^{\circ} \mathrm{C}$.

Air dried samples were cut into small pieces and soaked in $95 \%$ methanol $(1 \mathrm{~g}: 4 \mathrm{~mL})$ for one week. The crude extract was centrifuged and the centrifugate was concentrated under reduced pressure at $40^{\circ} \mathrm{C}$ using ro- 
tary evaporator (Buchi R-124).

The concentrated methanolic extract was placed in a separatory funnel and added with the same amount of hexane. The mixture was shaken thoroughly to extract the non-polar components from the crude methanolic extract. Layers were allowed to separate and the hexane layer was collected. The hexane layer was then subjected to rotary evaporation (Buchi $\mathrm{R}-124)$ under reduced pressure at $40^{\circ} \mathrm{C}$. The residue was collected in vials and kept at $-20^{\circ} \mathrm{C}$.

The crude methanolic extract was then subjected to extraction with chloroform to separate slightly polar components. The procedure was similar to that of hexane partition except that $10 \%$ distilled water was added to facilitate the separation of two partially immiscible layers.

The remaining methanolic extract in the separatory funnel was subjected to rotary evaporation, and the remaining solid was collected and kept at $-20^{\circ} \mathrm{C}$.

\section{Antitumor Screening}

Antitumor screening was done with the use of the brine shrimp (Artemia salina) lethality assay. Fortyeight hour old $A$. salina nauplii were used as test organisms. Brine shrimp eggs were hatched in an improvised two-compartment hatcher filled with artificial sea water (35g formulated salt/1L dH2O). Free swimming nauplii were gathered and plated in a 96 well microtiter plates (Dynatech Immulon).

A stock solution of $10,000 \mathrm{ppm}$ was prepared for each extract with the use of artificial sea water. Water insoluble extracts (hexane and chloroform) were first dissolved in $500 \mu \mathrm{L}$ dimethylsulfoxide (DMSO) (Merck) and then diluted to $1 \mathrm{~mL}$ with artificial sea water.

Different concentrations (20-2,000 ppm) each extract were prepared from their stock solution. Artificial sea water was used as negative control. Positive standards were also prepared with different concentrations. These are potassium dichromate, taxol (paclitaxel) (Bristol-Myer Squibb), Cytosine $\beta$-o-Arabinofuranoside (Ara-C) (Sigma Chemical Co.) and Etoposide (Sigma Chemical Co.).

One hundred microliter $(100 \mu \mathrm{L})$ of each working solutions for each extract was transferred in an individual well that contained $100 \mu \mathrm{L}$ artificial sea water with nauplii of a 96-well microtiter plate.

The numbers of dead nauplii were counted for each well after 6 hours and 24 hours to determine the acute and chronic concentration, respectively. Remaining live nauplii were killed by adding a few drop of formalde- hyde and the total nauplii per well were counted.

Data were analyzed using Reed Muench method [7]. Lethal concentration (LC50) and the 95\% confidence interval was determined using linear regression.

\section{Antimicrobial Assay}

The antimicrobial assay was done with the use of turbidimetric method and using E. coli as test organism. Aseptic condition was maintained all through out the assay.

- Test Organism Preparation

An inoculum of $E$. coli was applied in a prepared agar plate by streak plate method and incubated invertedly for 24 hours at $37^{\circ} \mathrm{C}$. After incubation, one colony from the agar plate (E. coli culture) was transferred to one of the prepared Lauria-Bertanni (LB) (Gibco BRL) broth and was placed in an incubator at $37^{\circ} \mathrm{C}$ for 24 hours. After incubation, $1 \mathrm{~mL}$ of $E$. coli culture (in broth) was diluted to $10 \mathrm{~mL}$ with sterile LB brothe (1 E. coli culture: 9 broth).

\section{Preparation of working solution}

Stock solution of 50,000 ppm was prepared for each extract using distilled water as solvent. Insoluble extracts were first dissolved in $40 \mu \mathrm{L}$ DMSO (Merck) before making to a final volume of $1,000 \mu \mathrm{L}$ with distilled water. Solutions were filter sterilized and working solutions of 2,000 ppm, 1,000 ppm, 200 ppm, $100 \mathrm{ppm}$ and $20 \mathrm{ppm}$ were prepared from the sterile stock solution.

Standard antibiotic solution were prepared by diluting Penicillin-Streptomycin [prepared with 5,000 units $/ \mathrm{mL}$ penicillin $\mathrm{G}$ sodium and $5,000 \mu \mathrm{g} / \mathrm{mL}$ streptomycin sulfate in $85 \%$ saline (Gibco BRL)] into $0.1 / 50,0.150,1 / 50,10 / 50,20 / 50$ and $30 / 50(\mathrm{v} / \mathrm{v})$

Fifty microliter $(50 \mu \mathrm{L})$ of the working solutions were transferred to individual wll of a sterile 96 wellmicro titer plate (Corning). Negative control was composed of $50 \mu \mathrm{L}$ distilled water and $50 \mu \mathrm{L}$ sterile LB broth. Fifty microliter $(50 \mu \mathrm{L})$ of prepared E. coli (1:9 dilution) was transferred to each well using a multipipettor. A positive blank composed of $50 \mu \mathrm{L}$ distilled water and $50 \mu \mathrm{L}$ of (1:9) diluted $E$. coli culture was also included in the bioassay. In addition, serial dilutions of $10-1,10-2,10-3$ and $10-4$ of E. coli were also included.

\section{Bioassay}

The microplates were then placed in plate shaker (Flow Laboratory, Titertek) and were shaken for 5 minutes. Optical densitites (absorbance) were determined at $650 \mathrm{~nm}$ wavelength using a microplate reader 
(Molecular Devices). Microplates were then placed in an incubator at $37^{\circ} \mathrm{C}$. The microplates were re-shaken and optical densities were measured after 4,8 and 24 hours of incubation.

\section{Microbial Count}

Four test tubes containing $9 \mathrm{~mL}$ sterile LB broth and five sterile nutrient agar plates were obtained. The tubes were labeled 10-1, 10-2,10-3 and 10-4 while the plates were labeled 10-1 to 10-5. One milliliter of prepared 1:9 E coli dilution was transferred to 10-1 labeled agar plate. The tube was then shaken vigorously and 1 and $0.1 \mathrm{~mL}$ of it were transferred to 10-2 labeled test tube and agar plate, respectively, and the tube was also shaken vigorously. The procedures were repeated to obtain a serial dilution of $10-1$ to $10-4$ and $10-1$ to $10-5$ of agar plate.

Fifty microliter $(50 \mu \mathrm{L})$ of each serial dilution was placed in each well of a 96 well microtiter plate and sterile distilled water was added to make a $100 \mu \mathrm{L}$ solution. A tenth of milliliter $(0.1 \mu \mathrm{L})$ of serial dilutions in agar plates were spread with the aid of a glass rod spreader. Plates were placed in an incubator invertedly for 24 hours. The colonies formed after 24 hours were counted using a semi-automated colony counter (Stuart).

\section{Data Analysis}

The minimum inhibitory concentration (MIC) and minimum bactericidal concentration $(\mathrm{MBC})$ of various extracts after 4, 8 and 24 hours of exposure were determined using linear regression. Absorbance reading was correlated to CFU (colony forming unit) to determine the bacterial count.

\section{RESULTS AND DISCUSSION}

Brine shrimp lethality assay was used to determine the antitumor activity of the different solvent extracts of echinoderms. This assay has been established as rapid and simple method for screening starfish extracts for antitumor activity $[8,9]$. Table 1 showed the LC50 values of the different extracts after 6 (acute) and 24 (chronic) hours of exposure.

The chloroform extract of Holothuria nobilis had an LC50 of less than $10 \mathrm{ppm}$, the lowest concentration used for all the extracts. It may be considered to contain antitumor agents since the standard set by the National Cancer Institute of the US for a bioactive compound to be an effective antitumor agent is equal or less than $30 \mathrm{ppm}$. The extract appears also more potent and more toxic (acute) compare to the commercial anticancer drugs Taxol, Etoposide and Ara$\mathrm{C}$ used in the experiment.

Extracts, which have close value to the set standard, include the chloroform and hexane extracts of $\mathrm{H}$. axiologa which has a chronic LC50 value of $37.48 \mathrm{ppm}$ and $63.42 \mathrm{ppm}$, respectively and the chloroform extract of $S$. chloronatus with chronic LC50 value of 52.16 ppm. These extracts also have higher acute toxicities in comparison to the standard anticancer drugs. In addition, only two positive controls have LC50 below the $30 \mathrm{ppm}$ standard, potassium dichromate with an LC50 of $20.29 \mathrm{ppm}$ and Taxol with an LC50 of11.05 ppm. All anticancer drugs even have acute LC50 values greater than $1000 \mathrm{ppm}$.

Previous researches on cytotoxic properties of echinoderm extracts were mostly focused on their glycosides, particularly the saponin and saponin-like components. From the results, only sea cucumber samples showed antitumor activity. Cytotoxic activities were reported on active components like the alcohol extracts from $H$. impatiens $[10,11]$, the glycosides such as the desulfated derivatives of calcigerosides from Pentamera calcigera [12-15], liouvillosides from Staurocucumis liouvellei [16-18], hemoiedemosides from Hemoiedema spectabilis [19] and anti-tumor lectins from brown sea cucumbers [20]. Other components in sea cucumbers which showed high cytotoxic activities include echinosides, holothurins, holotoxin and cucumarioside [21].

It is surprising that starfishes failed to show antitumor activities in brine shrimps as studies have reported cytotoxic activities in starfishes such as Narcissia canariensis [22], Certonardoa semiregularis [9, 23], Culcita novaeguineae [24] and Acanthester planci [25]. In the study on $A$. planci, it can be noted that as solvent extracts which showed cytotixicty seemed to have lost activity upon sequential extraction [25]. Antitumor activity that depends on metabolic activation may also lead to false-negatives [26].

All echinoderms showed antibacterial activity against E. coli (tables 2A, 2B, 2C). Extracts from the four sea cucumber species showed different activity. The methanol extracts from sea cucumbers showed negative results with the exception of that of $H$. axiologa. Hexane and methanol extracts of $H$. nobilis were active at 4 hours of exposure but their effectiveness declined with time. The same thing can be observed on the aqueous extract whose activity started only after 8 hours of exposure.

Anti-microbial activity of chloroform extract from B. marmorata increased relatively with time from 4 to 8 hours but declined after 24 hours. The activity of the 
aqueous and hexane extracts, which is most active at 4 hours, also declined with time. The chloroform extracts of Stichopus chloronatus was the most effective bactericidal while the hexane extract was the most effective bacteriostat. Inhibition was observed with time in the three extracts other than the methanol extract. Lastly, in $H$. axiologa, the hexane extracts did not exhibit activity while its methanol extract showed activity after 8 hours of exposure but ceased after 24 hours that could made it a potential bacteriostat. The most active is chloroform extract showing activity at 4 hours of exposure and also a possible bacteriostat while aqueous extract after showing activity at 8 hours lessened relatively with time.

The activities of the different extracts showed the different nature of substances present in the sea cucumbers. H. nobilis, Bohadschia marmorata and Stichopus chloronatus have antibacterial activities in all extracts with the exception of methanol. This is in comparison with $H$. axiologa which had the hexane extract as the inactive fraction. hand showed bacteriostatic activity. In addition, the chloroform extract have its stronger activity at 4 hours while the hexane extract showed activity only at 8 hours of exposure.

Lastly, for the brittlestar Ophiocoma ochoenleinii, the methanol extract was inactive against $E$. coli while hexane extract showed becteriostatic activity at 4 hours of exposure but ceased at 8 hours. Chloroform was the most potent however its activity decreased relatively with time until 8 hours of exposure and ceased at 24 hours.

Studies done about the anti-microbial properties of echinoderm extracts were mainly focus on their glycosides component, particularly the saponin (triterpene glycosides) and saponin-like components that are present on the polar fraction of echinoderm samples [27-31]. Some exhibit anti-microbial activities against fungi, yeast and viruses, however, but not against gram $(+)$ and gram (-) bacteria [32]. While others display anti-bacterioside activity in aqueous-extracts but in ethanolic and lipid extracts [33].

Table 1. $\mathrm{LC}_{50}$ of echinoderms extracts against brine shrimp

\begin{tabular}{|c|c|c|c|}
\hline Sample & Extracts & LC (6) (6 hours) & LC $_{\text {so }}(24$ hours $)$ \\
\hline \multirow[t]{4}{*}{ Holothuria nobilis } & aqueous & $>1000$ & \\
\hline & methanol & 351.03 & 105.61 \\
\hline & chloroform & 53.6 & $<10$ \\
\hline & hexane & $>1000$ & 125.42 \\
\hline \multirow[t]{4}{*}{ Bohadscia marmorata } & aqueous & $>1000$ & \\
\hline & methanol & $>1000$ & $>1000$ \\
\hline & chloroform & $>1000$ & 156.37 \\
\hline & hexane & $>1000$ & 350.06 \\
\hline \multirow[t]{4}{*}{ Stichopus chloronatus } & aqueous & & \\
\hline & methanol & & 141.25 \\
\hline & chloroform & 177.14 & 52.16 \\
\hline & hexane & $>1000$ & $>1000$ \\
\hline \multirow[t]{4}{*}{ Holothuria axiologa } & aqueous & $>1000$ & 302.98 \\
\hline & methanol & 305.34 & 96.74 \\
\hline & chloroform & 84.38 & 37.48 \\
\hline & hexane & 602.98 & 63.42 \\
\hline \multirow[t]{4}{*}{ Linckia laevigata } & aqueous & & \\
\hline & methanol & $>1000$ & $>1000$ \\
\hline & chloroform & & \\
\hline & hexane & $>1000$ & 215.84 \\
\hline \multirow[t]{4}{*}{ Oreaster nodusus } & aqueous & & \\
\hline & methanol & $>1000$ & \\
\hline & chloroform & $>1000$ & 257.04 \\
\hline & hexane & $>1000$ & 138.04 \\
\hline \multirow[t]{4}{*}{ Ophiocoma ochoenleinif } & aqueous & $>1000$ & $>1000$ \\
\hline & methanol & $>1000$ & $>1000$ \\
\hline & chloroform & $>1000$ & 107.15 \\
\hline & hexane & & \\
\hline
\end{tabular}

For the starfishes, three extract were screened for antibacterial activity. Chloroform, methanol and hexane extracts of Linckia laevigata showed after 8 hours of exposure but immediately ceased at 24 hours. The chloroform extract of Oreaster nodusus on the other
On the other hand, that of starfishes and brittle stars, were inactive against gram negative bacteria $E$. coli and some show activities against gram-positive bacteria $S$. aureus, including the polyhydroxylated steroid glycosides, polyhydroxylated sterol and disul- 
fated sterol [34].

Results showed that the methanolic extracts of sea cucumber samples were inactive against $E$. coli except that of $H$. axiologa. These agree with the observation of [32]. observed that the results of hexane and methanol extracts of $L$. laevigata were very closely similar (both were inactive at 4 and 24 hours exposure and have very close MIC and MBC values at 8 hours exposure). Furthermore, the methanolic extracts of both samples were

Table 2. Minimum inhibitory concentration (MIC) and minimum bactericidal concentration (MBC) of echinoderms extracts against E. coli after: A. 4 hours of exposure, B. 8 hours of exposure, C. 24 hours of exposure

\begin{tabular}{|cccc|}
\hline \multirow{3}{*}{ Sample } & Extracts & MIC $(\mu \mathrm{g} / \mathbf{m L})$ & MBC $(\boldsymbol{\mu g} / \mathbf{m L})$ \\
\hline H. nobilis & aqueous & 1431 & 4 \\
& methanol & 40 & $<1$ \\
& chloroform & 21 & 2556 \\
& hexane & 76 & 793 \\
\hline B. marmorata & aqueous & 699 & 2558774 \\
& methanol & 955 & $<1$ \\
& chloroform & 46 & 1631 \\
& hexane & 140480 & 3524 \\
\hline S. chloronatus & aqueous & 213 & 106096 \\
& methanol & 1 & $<1$ \\
& chloroform & 117 & 286 \\
& hexane & 2 & 10872147 \\
\hline H. axiologa & aqueous & 17 & $<1$ \\
& methanol & 31 & $<1$ \\
& chloroform & 194 & 49396 \\
& hexane & 16 & $<1$ \\
\hline O. ochoenleinii & hexane & 28.10 & 18226 \\
\hline Penicillin/Streptomycin & $<1$ & 949 \\
\hline & & & \\
\hline
\end{tabular}

A

\begin{tabular}{|c|c|c|c|}
\hline Sample & Extracts & MIC $(\mu \mathrm{g} / \mathrm{mL})$ & $\mathrm{MBC}(\mu \mathrm{g} / \mathrm{mL})$ \\
\hline \multirow[t]{4}{*}{ H. nobilis } & aqueous & 179 & 2723 \\
\hline & methanol & 116 & 112 \\
\hline & chloroform & 369 & 3711 \\
\hline & hexane & 340 & 979 \\
\hline \multirow[t]{4}{*}{ B. marmorata } & aqueous & 808 & 26103 \\
\hline & methanol & 3 & $<1$ \\
\hline & chloroform & 150 & 2480 \\
\hline & hexane & 403 & 4335 \\
\hline \multirow[t]{4}{*}{ S. chloronatus } & aqueous & 24 & 5 \\
\hline & methanol & 1 & $<1$ \\
\hline & chloroform & 12 & 2 \\
\hline & hexane & 21 & 1 \\
\hline \multirow[t]{4}{*}{ H. axiologa } & aqueous & 8072 & 3547755 \\
\hline & methanol & 816 & 92076 \\
\hline & chloroform & 250 & 2615 \\
\hline & hexane & 29 & 6 \\
\hline \multirow[t]{3}{*}{ O. ochoenleinii } & methanol & 42 & 3 \\
\hline & chloroform & 46 & 1305 \\
\hline & hexane & 20 & $<1$ \\
\hline Penicillin/Stre & omycin & $<1$ & 1005 \\
\hline
\end{tabular}

B

\begin{tabular}{|c|c|c|c|}
\hline Sample & Extracts & $\operatorname{MIC}(\mu \mathrm{g} / \mathrm{mL})$ & $\operatorname{MBC}(\mu \mathrm{g} / \mathrm{mL})$ \\
\hline \multirow{4}{*}{ H. nobilis } & aqueous & 1182 & 5966 \\
\hline & methanol & $<0.01$ & $<0.01$ \\
\hline & chloroform & 8004 & 36714 \\
\hline & hexane & 3041 & 9304.94 \\
\hline \multirow[t]{4}{*}{ B. marmorata } & aqueous & 116691 & 2088073 \\
\hline & methanol & 0.22 & 0.02 \\
\hline & chloroform & 2597 & 562552 \\
\hline & hexane & 1319 & 4314 \\
\hline \multirow[t]{4}{*}{ S. chloronatus } & aqueous & 6263 & 173004 \\
\hline & methanol & $<0.01$ & $<0.01$ \\
\hline & chloroform & 2748 & 8726 \\
\hline & hexane & 2 & 0.17 \\
\hline \multirow[t]{4}{*}{ H. axiolog $a$} & aqueous & 11755 & 102272 \\
\hline & methanol & 0.5 & 0.04 \\
\hline & chloroform & 6952 & 26529 \\
\hline & hexane & $<0.01$ & $<0.01$ \\
\hline \multirow[t]{3}{*}{ O. ochoenleinï } & methanol & 1.6 & 0.27 \\
\hline & chloroform & 0.4 & $<0.01$ \\
\hline & hexane & 1.1 & 0.08 \\
\hline Penicillin/Stre & mycin & 248 & 962 \\
\hline
\end{tabular}

C

Observations on saponin and saponin-like components of sea stars indicate that they are inactive against E. coli [34]. These are contrary to the results of two sea star samples (L. laevigata and $O$. nodusus), since both indicated of showing anti-microbial activity. We also found to be insoluble in distilled water. Chances are the polar and non-polar extracts of the L. laevigata that were tested are identical and errors during extraction of both sea star samples could have been occurred.

Methanolic extracts of $O$. ochoelenii was also inac- 
tive against E. coli similar to a previous study [34]. On the other hand, anti-bacterial activities among the hexane and chloroform extracts of all the echinoderm samples were observed with the exception of $H$. axiologa. These results indicate presence of different groups of biologically active substances among echinoderm samples that exhibit anti-microbial properties, which possibly, are not yet fully studied, and could be modified into a new anti-microbial drug, if given further attention. Aqueous extracts were also found to express antimicrobial activity against $E$. coli.

An antibiotic is considered bacteriostatic if it yields low MIC but high MBC values. Accordingly, the following extract probably may contain short-term bacteriostatic substances: chloroform extract of $H$. nobilis, Hexane and aqueous extracts of $S$. chloronatus, and hexane extracts of $B$. marmorata and $O$. ochoeleinii. Aqueous extracts of $B$. marmorata have longer-acting inhibitory property in 4,8 and 24 hours of exposure. A delay in inhibition was observed for both from extracts H. axiologa.

A bacteriostatic agent, given in sufficient doses to increase the concentration, may exhibit bactericidal activity. Similarly, extremely low doses of a bactericidal drugs may merely exhibit bacteriostatic activity.

From our screen, we found that the chloroform extract of $S$. chloronatus contains the most potent bactericide having $\mathrm{MBC}$ value of $282.90 \mathrm{ppm}$ (3.33x more potent than Penicillin-Streptomycin) while its hexane extract is most bacteriostatic having an MIC and MBC values of $2.29 \mathrm{ppm}$ and 10,872, $146 \mathrm{ppm}$ respectively.

\section{CONCLUSIONS}

Different solvent extracts of seven Philippine echinoderms were screened for antitumor and antibacterial agents. The chloroform extract of $H$. nobilis contain a potential anti-tumor agent that is more potent and more toxic (acute) than Taxol, Etoposide and AraC. Hexane and chloroform extracts of $H$. axiologa and chloroform extracts of $S$. chloronatus also exhibit weak antitumor activities against brine shrimp and are more toxic (acute) than the standard anticancer drugs.

All samples contain substances that exhibit antibacterial activity against $E$. coli. Some only exhibit a bacteriostatic activity against $E$. coli but there are others that exhibit bacteriocidal effect.

\section{ACKNOWLEDGMENT}

We are grateful to Violeta G. Bautista of the $\mathrm{Na}$ tional museum for species identification.

\section{REFERENCES}

1. Pechenik JA (2005) Biology of the Invertebrates. McGrawHill, Higher Education. Boston.

2. Blunt JW, Copp BR, Hu WP, Munro M, Northcote PT, Prinsep MR (2007) Marine natural products. Natural Product Reports. 24: 31.

3. Kelly M (2005) Echinoderms: their culture and bioactive compounds in Echinodermata. Springer. 139-165.

4. Sima P, Vetvicka V (2011) Bioactive substances with antineoplastic efficacy from marine invertebrates: Porifera and Coelenterata. World journal of clinical oncology. 2: 355.

5. Fusetani N (2012) Marine Natural Products. Natural Products in Chemical Biology. 31.

6. Caulier G, Van Dyck S, Gerbaux P, Eeckhaut I, Flammang P (2011) Review of saponin diversity in sea cucumbers belonging to the family Holothuridae. SPC Beche-demer Inf Bull. 31: 48-54.

7. Reed LJ, Muench H (1938) A simple method of estimating fifty per cent endpoints. American Journal of Epidemiology. 27: 493-497.

8. Chludil HD, Maier MS (2005) Minutosides A and B, antifungal sulfated steroid xylosides from the patagonian starfish Anasterias minuta. Journal of natural products. 68: 1279-83.

9. Wang W, Jang H, Hong J, Lee CO, Bae SJ, Shin S, Jung JH (2005) New cytotoxic sulfated saponins from the starfish Certonardoa semiregularis. Archives of pharmacal research. 28: 285-9.

10. Carballo JL, Hernández-Inda ZL, Pérez P, García-Grávalos MD (2002) A comparison between two brine shrimp assays to detect in vitro cytotoxicity in marine natural products. BMC biotechnology. 2: 17.

11. Sun P, Liu BS, Yi YH, Li L, Gui M, Tang HF, Zhang DZ, Zhang SL (2007) A New Cytotoxic Lanostane-Type Triterpene Glycoside from the Sea Cucumber Holothuria impatiens. Chemistry \& Biodiversity. 4: 450-457.

12. Kim SK, Himaya S (2012) Triterpene glycosides from sea cucumbers and their biological activities. Advances in food and nutrition research. 65: 297.

13. Avilov SA, Silchenko AS, Antonov AS, Kalinin VI, Kalinovsky AI, Smirnov AV, Dmitrenok PS, Evtushenko EV, Fedorov SN, Savina AS (2008) Synaptosides A and A1, triterpene glycosides from the sea cucumber Synapta maculata containing 3-O-methylglucuronic acid and their cytotoxic activity against tumor cells. Journal of natural products. 71: 525-531.

14. Avilov SA, Antonov AS, Drozdova OA, Kalinin VI, Kalinovsky AI, Stonik VA, Riguera R, Lenis LA, Jiménez C (2000) Triterpene glycosides from the Far-Eastern sea cucumber Pentamera calcigera. 1. Monosulfated glycosides and cytotoxicity of their unsulfated derivatives. Journal of 
natural products. 63: 65-71.

15. Maier MS (2008) Biological activities of sulfated glycosides from echinoderms. Studies in Natural Products Chemistry. 35: 311-354.

16. Antonov AS, Avilov SA, Kalinovsky AI, Anastyuk SD, Dmitrenok PS, Evtushenko EV, Kalinin VI, Smirnov AV, Taboada S, Ballesteros M (2008) Triterpene glycosides from Antarctic sea cucumbers. 1. Structure of Liouvillosides A1, A2, A3, B1, and B2 from the sea cucumber Staurocucumis liouvillei: new procedure for separation of highly polar glycoside fractions and taxonomic revision. Journal of natural products. 71: 1677-1685.

17. Maier MS, Roccatagliata AJ, Kuriss A, Chludil H, Seldes AM, Pujol CA, Damonte EB (2001) Two new cytotoxic and virucidal trisulfated triterpene glycosides from the Antarctic sea cucumber Staurocucumis liouvillei. Journal of natural products. 64: 732-736.

18. Antonov AS, Avilov SA, Kalinovsky AI, Dmitrenok PS, Kalinin VI, Taboada S, Ballesteros M, Avila C (2011) Triterpene glycosides from Antarctic sea cucumbers III. Structures of liouvillosides A4 and A5, two minor disulphated tetraosides containing 3-O-methylquinovose as terminal monosaccharide units from the sea cucumber Staurocucumis liouvillei (Vaney). Natural Product Research. 25: 1324-1333.

19. Chludil HD, Muniain CC, Seldes AM, Maier MS (2002) Cytotoxic and Antifungal Triterpene Glycosides from the Patagonian Sea Cucumber Hemoiedema s pectabilis. Journal of natural products. 65: 860-865.

20. Gana A (2002) Isolation and purification of a cytotoxic lectin from brown sea cucumber by affinity chromatography. Philippine Agricultural Scientist. 85. 